\title{
Bridging the gap between theoretical ecology and real ecosystems: modeling invertebrate community composition in streams
}

\author{
Nele Schuwirth ${ }^{1}$ and Peter Reichert \\ Eawag - Swiss Federal Institute of Aquatic Science and Technology, 8600 Dübendorf, Switzerland
}

\begin{abstract}
For the first time, we combine concepts of theoretical food web modeling, the metabolic theory of ecology, and ecological stoichiometry with the use of functional trait databases to predict the coexistence of invertebrate taxa in streams. We developed a mechanistic model that describes growth, death, and respiration of different taxa dependent on various environmental influence factors to estimate survival or extinction. Parameter and input uncertainty is propagated to model results. Such a model is needed to test our current quantitative understanding of ecosystem structure and function and to predict effects of anthropogenic impacts and restoration efforts. The model was tested using macroinvertebrate monitoring data from a catchment of the Swiss Plateau. Even without fitting model parameters, the model is able to represent key patterns of the coexistence structure of invertebrates at sites varying in external conditions (litter input, shading, water quality). This confirms the suitability of the model concept. More comprehensive testing and resulting model adaptations will further increase the predictive accuracy of the model.
\end{abstract}

Key words: allometric scaling; Bayesian inference; biotic interactions; coexistence; food web model; functional traits; invertebrates; stoichiometry; trait databases; uncertainty.

\section{INTRODUCTION}

The derivation of generic results that demonstrate the instability of complex food webs (e.g., May 1973, Pimm and Lawton 1978, Yodzis 1981) led to an intensive "diversity-stability debate" in ecology (e.g., McCann 2000). However, in recent years, some progress has been made in finding explanations for stability of complex food webs (e.g., Brose et al. 2006, Clark et al. 2007, Heckmann et al. 2012). Such revised food web theories include allometric scaling as summarized in the metabolic theory of ecology (MTE; Brown et al. 2004) and revised definitions of stability that allow for dynamic equilibria (e.g., McCann 2000). Most of the conceptual results about stability of complex food webs cited above were derived from ensembles of food webs represented by a sample of randomly generated structures. This is an important research strategy to derive or verify generic results that improve our general understanding of phenomena in theoretical ecology. However, it is possible that real networks have properties that significantly deviate from such randomly generated structures (McCann 2000).

To profit from this generic knowledge for understanding real food webs and predicting their future behavior, we go a step closer to reality by using properties of real invertebrate taxa in a specific river catchment. The theories mentioned above leave enough freedom for such adaptations. It has been realized for

Manuscript received 12 April 2012; revised 27 July 2012; accepted 21 August 2012. Corresponding Editor: D. C. Speirs.

${ }^{1}$ E-mail: nele.schuwirth@eawag.ch quite a long time that allometric scaling leads to astonishingly good fits of basal metabolic rates over about 20 orders of magnitude of individual biomass (Brown et al. 2004):

$$
\tilde{r}_{\text {basal metab }}=i_{0}\left(\frac{M}{M_{0}}\right)^{b} e^{-E / k T}
$$

where $\tilde{r}_{\text {basal metab }}$ is the individual basal metabolic rate as energy turnover per time (in watts, W), $i_{0}$ a normalization constant (W), $E$ the activation energy $(\mathrm{eV} ; 1 \mathrm{eV}=$ $\left.1.602 \times 10^{-19} \mathrm{~J}\right), k$ Boltzmann's constant $8.617343 \times$ $10^{-5} \mathrm{eV} / \mathrm{K}, T$ is absolute temperature $(\mathrm{K}), b$ an allometric scaling exponent, $M$ the biomass of the individual $(\mathrm{g})$, and $M_{0}$ is set to $1 \mathrm{~g}$. However, much variation over narrower ranges of biomass remains unexplained. Brown et al. (2004) found variation in normalization constants by a factor of up to 20 across taxonomic groups. As there are many more influencing factors on metabolic processes than temperature and body mass, this variation is not surprising. But it is important for understanding real ecosystems. There has been a long debate on the allometric scaling exponent $b$ (Eq. 1), of being 2/3 (Rubner 1883) or 3/4 (Kleiber 1947, Peters 1983, West et al. 1997, Savage et al. 2004). More recent (and accurate) empirical evidence has clarified that neither "law" is universal and there may not even be a single universal exponent (Glazier 2009, White 2010). Nevertheless, the use of such an approximate allometric scaling relationship, possibly based on an empirical exponent, has proven to be useful in food web models to make them more realistic, reduce the number of free parameters (Yodzis and Innes 1992, Traas et al. 1998) 
and increase their stability (Brose et al. 2006, Brose 2008). For the same reasons, we use the relationship in Eq. 1 as the basis of our model.

Similarly, stoichiometric considerations lead to constraints, e.g., in achievable yields based on food quality (e.g., Elser and Hassett 1994, Hessen et al. 2002, Andersen et al. 2004), and allow coupling of organism metabolic rates to nutrient cycling. However, stoichiometry still leaves enough scope for taxonomic variation (Elser et al. 2000a, $b$ ).

Functional trait databases offer new opportunities for accessing functionally relevant knowledge about invertebrate taxa that could help resolve part of this variation (e.g., Doledec et al. 2011). Important environmental factors controlling the distribution of stream dwelling invertebrates are, for example, current speed, temperature regime (including altitude and season), substratum type (including vegetation), and dissolved substances (Hynes 1970). These factors act as so called "landscape filters" (Poff 1997) determining the potential occurrence of taxa dependent on their functional traits. However, it has long been recognized that biotic interactions like competition and predation also play an important role in community structure (Hairston et al. 1960), which are not included in classical habitat models (see review in Guisan and Thuiller [2005]). Other factors influencing the presence or absence of taxa are biogeography, colonization potential, susceptibility to short-term disturbance (e.g., drought and floods), and food availability. It seems thus a relevant step to bring together food web theories, allometric scaling and biological stoichiometry with the use of functional trait databases and geographical information to build-up meta-community models that would account for these different, important influencing factors.

In this paper, we make a first step by constructing a benthic macroinvertebrate community model Streambugs 1.0 to test the feasibility of this concept. We start by combining the theoretical models with actual biological trait information to reproduce the benthic community composition at sites in a catchment that differ in their external driving conditions. Aim is to predict, which taxa generally occur and which taxa never occur at each site using a Bayesian approach. To do so, we only need the stable steady-state (or potentially oscillating) long-term solutions of the model that represent the coexistence of different taxa at the site. Process formulations for growth, respiration, and death are similar to food web models for functional groups of stream-dwelling organisms developed, e.g., by McIntire and Colby (1978), Power et al. (1995), D'Angelo et al. (1997), Spieles and Mitsch (2003), and Schuwirth et al. (2008, 2011). These models intended to describe key functions of the ecosystem, like primary production, primary and secondary consumption, and turnover of organic material. However, other features important for river assessment, such as biodiversity and the occurrence of sensitive species, are not captured by such models. To address these issues, food web models describing the coexistence of individual taxa are needed, as in this study.

\section{Material and Methods \\ Model development concept}

To improve understanding of the factors determining the composition of benthic macroinvertebrate (see Plate 1) communities in streams, we developed a model that works at the taxonomic level instead of describing functional groups and uses functional trait information to parameterize processes. State variables can be species, genera, or families (or even different taxonomic levels for different taxa), depending on the available trait information and on the taxonomic resolution of the observational data the model results should be compared with. To not increase the number of parameters compared to the functional group approach, we use allometric scaling according to MTE to parameterize the basic specific growth, death, and respiration rates. Thus, only an estimate of temperature and the mean body mass for each taxonomic group is needed. The other parameters are universal for all taxonomic groups. However, to account for variation of individual taxa around MTE predictions, we include one taxa-specific modification parameter for the basal metabolic rate and one for the growth rate. Process rates are furthermore modified considering functional traits of the taxa. Our concept of model development consists of the steps outlined in the following subsections.

Step 1: Mass balances and stoichiometry.-The model includes individual invertebrate taxa, periphyton, and fine and coarse particulate organic matter (FPOM, CPOM) as state variables. We chose benthic (bio)mass per unit river length as dimension of the state variables, as this quantity is conserved under water level changes. The following processes are included in the food web model: growth, respiration, and mortality of primary producers and invertebrate consumers, and input of leaf litter. Feeding types of invertebrate taxa were derived from trait databases. Unless detailed feeding relationships are known, predators were assumed to feed on all taxa with a smaller mean biomass than themselves. Based on the assumed composition and energy content of invertebrates, periphyton, and organic matter, and on the values of a few stoichiometric parameters, the stoichiometric coefficients $\left\{v_{i j}\right\}$ of these processes are derived as outlined in Reichert and Schuwirth (2010). They were automatically calculated with the $\mathrm{R}$ package stoichcalc (Reichert and Schuwirth 2010). Nutrients and oxygen were included in the mass balance to derive stoichiometric coefficients, but they were not modeled as state variables.

We denote the biomass per river length as $B$ (g DM/ $\mathrm{m}$, where DM is dry mass) and the biomass surface density as $D\left(\mathrm{~g} \mathrm{DM} / \mathrm{m}^{2}\right)$ that can be derived from $B$ divided by the stream width $w$. The process rates and stoichiometric coefficients are given in the form of a 
TABLE 1. Process table of the model including stoichiometric parameters and process rates.

\begin{tabular}{|c|c|c|c|c|c|c|c|c|}
\hline \multirow[b]{2}{*}{ Processes } & \multicolumn{7}{|c|}{ State variables } & \multirow[b]{2}{*}{ Process rates } \\
\hline & $\begin{array}{l}\text { Periphyton } \\
\text { (g DM) }\end{array}$ & $\begin{array}{c}\text { Invert. } \\
\text { taxa (g DM) }\end{array}$ & $\begin{array}{l}\text { Litter } \\
\text { (g DM) }\end{array}$ & $\begin{array}{c}\text { FPOM } \\
(\text { g DM) }\end{array}$ & $\begin{array}{c}\text { Food } \\
(\text { g DM) }\end{array}$ & Nutrients & Oxygen & \\
\hline pp gro & 1 & & & & & - & + & $r_{\mathrm{gro}}^{\mathrm{pp}}\left(\mathrm{g} \mathrm{DM} \cdot \mathrm{yr}^{-1} \cdot \mathrm{m}^{-2}\right)$ \\
\hline pp resp & -1 & & & & & + & - & $r_{\mathrm{resp}}^{\mathrm{pp}}\left(\mathrm{g} \mathrm{DM} \cdot \mathrm{yr}^{-1} \cdot \mathrm{m}^{-2}\right)$ \\
\hline pp mort & -1 & & & $+Y_{\text {mort }}$ & & $+/ 0$ & $+/ 0$ & $r_{\text {mort }}^{\mathrm{pp}}\left(\mathrm{g} \mathrm{DM} \cdot \mathrm{yr}^{-1} \cdot \mathrm{m}^{-2}\right)$ \\
\hline cons gro & & +1 & & $+\mathrm{f}_{\mathrm{e}} / Y_{\text {gro }}$ & $-1 / Y_{\text {gro }}$ & $+/ 0$ & $+/-$ & $r_{\mathrm{gro}}^{\text {cons }}\left(\mathrm{g} \mathrm{DM} \cdot \mathrm{yr}^{-1} \cdot \mathrm{m}^{-2}\right)$ \\
\hline cons resp & & -1 & & & & + & - & $r_{\text {resp }}^{\text {cons }}\left(\mathrm{g} \mathrm{DM} \cdot \mathrm{yr}^{-1} \cdot \mathrm{m}^{-2}\right)$ \\
\hline cons mort & & -1 & & $+Y_{\text {mort }}$ & & $+/ 0$ & $+/ 0$ & $r_{\text {mort }}^{\text {cons }}\left(\mathrm{g} \mathrm{DM} \cdot \mathrm{yr}^{-1} \cdot \mathrm{m}^{-2}\right)$ \\
\hline Litter inp & & & +1 & & & & & $r_{\text {inp }}^{\text {litter }}\left(\mathrm{g} \mathrm{DM} \cdot \mathrm{yr}^{-1} \cdot \mathrm{m}^{-2}\right)$ \\
\hline
\end{tabular}

Notes: The stoichiometric coefficients labeled with signs only are calculated as explained in Reichert and Schuwirth (2010). Abbreviations for state variables are: invert. taxa, invertebrate taxa; litter, leaf litter; FPOM, fine particulate organic matter; DM dry mass. Depending on the feeding type of the consumer, "food" can be other invertebrate taxa, periphyton, litter, FPOM, and/ or SusPOM (suspended particulate organic matter). Processes are growth of primary producers (pp gro), respiration of primary producers ( $\mathrm{pp}$ resp), mortality of primary producers ( $\mathrm{pp}$ mort), growth of consumers (cons gro), respiration of consumers (cons resp), mortality of consumers (cons mort), and input of leaf litter (litter inp). Process rates are growth rate of primary producers $\left(r_{\mathrm{gro}}^{\mathrm{pp}}\right)$, respiration rate of primary producers $\left(r_{\mathrm{resp}}^{\mathrm{pp}}\right)$, mortality rate of primary producers $\left(r_{\text {mort }}^{\mathrm{pp}}\right)$, growth rate of invertebrate consumers $\left(r_{\text {gro }}^{\text {cons }}\right)$, respiration rate of invertebrate consumers $\left(r_{\text {resp }}^{\text {cons }}\right)$, mortality rate of invertebrate consumers $(r$ mort $)$, and rate of leaf litter input $\left(r_{\text {inp }}^{\text {litter }}\right) . Y_{\text {gro }}$ is yield for growth according to Eq. 3, $Y_{\text {mort }}$ is yield for death process according to Eq. 4, $f_{\mathrm{e}}$ is fraction of fine particulate organic matter (FPOM) produced by excretion and sloppy feeding. Empty cells mean that the state variable in that column is not involved in the process of that row.

process table (Reichert and Schuwirth 2010) in Table 1. The differential equations for the biomasses of all taxa and of organic matter per river length $\mathbf{B}=\left(B_{1}, \ldots, B_{n}\right)$ can be constructed from the stoichiometric coefficients $\boldsymbol{v}$ $=\left\{v_{i j}\right\}$ for the processes and organisms $/$ substances given in the process table (Table 1) and the dynamic rates $\mathbf{r}=$ $\left(r_{1}, \ldots, r_{m}\right)\left(\mathrm{g} \mathrm{DM} \cdot \mathrm{m}^{-2} \cdot \mathrm{yr}^{-1}\right)$, which depend on the parameters $\boldsymbol{\theta}$, according to

$$
\frac{d \mathbf{B}}{d t}=\boldsymbol{v} \cdot \mathbf{r}\left(\frac{\mathbf{B}}{w}, \boldsymbol{\theta}\right) w
$$

All parameters are summarized in Appendix: Table A1.

Formally, the growth process of invertebrates consists of building reserves. Mineralization of the food is combined with mineralization of reserves in the respiration process. The yield $Y_{\text {gro }}$ describes assimilation efficiency and takes into account differences in energy content and elemental composition of the consumer and its food source. Deriving or constraining stoichiometric coefficients and yields by elemental mass balances allows us to consider limitations of yield due to food quality (e.g., Elser and Hassett 1994, Hessen et al. 2002, Andersen et al. 2004) and prepares the model for a later coupling with biogeochemical cycles. As long as no detailed information about the elemental composition of different organisms is available, we assume a Redfield composition for all organic constituents:

$$
\begin{aligned}
Y_{\text {gro }}=\min \left(1, \frac{\mathrm{EC}_{\text {food }}-f_{\mathrm{e}} \times \mathrm{EC}_{\mathrm{FPOM}}}{\mathrm{EC}_{\mathrm{cons}}},\right. \\
\left.\frac{\alpha_{\mathrm{N} \text { food }}-f_{e} \times \alpha_{\mathrm{N} \mathrm{FPOM}}}{\alpha_{\mathrm{N} \text { cons }}}, \frac{\alpha_{\mathrm{P} \text { food }}-f_{\mathrm{e}} \times \alpha_{\mathrm{P} \mathrm{FPOM}}}{\alpha_{\mathrm{P} \text { cons }}}\right)
\end{aligned}
$$

where EC denotes the energy content $(\mathrm{J} / \mathrm{g} \mathrm{DM})$, and $\alpha_{\mathrm{P}}$ and $\alpha_{N}$ are the phosphorus and nitrogen contents, respectively (g P/g DM, g N/g DM). The fraction of FPOM produced by excretion and sloppy feeding is characterized by the parameter $f_{\mathrm{e}}$. To close the mass balances (for the elements $\mathrm{C}, \mathrm{N}, \mathrm{P}, \mathrm{O}, \mathrm{H}$, and charge) the remaining fraction of biomass is assumed to be released as dissolved nutrients.

During the death process, living biomass is transformed to organic matter. Since the model includes only one state variable of FPOM and the elemental composition and the energy content of organisms and FPOM may be different, the mass balance of this process is closed by introducing a "yield," $Y_{\text {mort }}$. This term guarantees that as much as possible of the biomass is transferred to FPOM, and the remaining fraction is released as dissolved nutrients, similar to the growth process:

$$
Y_{\text {mort }}=\min \left(1, \frac{\mathrm{EC}_{\mathrm{cons}}}{\mathrm{EC}_{\mathrm{FPOM}}}, \frac{\alpha_{\mathrm{N} \text { cons }}}{\alpha_{\mathrm{N} \mathrm{FPOM}}}, \frac{\alpha_{\mathrm{P} \text { cons }}}{\alpha_{\mathrm{P} \mathrm{FPOM}}}, Y\left(v_{\mathrm{O} 2}=0\right)\right)
$$

where $Y\left(v_{\mathrm{O} 2}=0\right)$ denotes the yield at which the stoichiometric coefficient of oxygen is zero; this term ensures, that no oxygen is consumed by the death process. This is desirable, since the death process should not depend on the presence of oxygen (in contrary, organisms would die in the absence of oxygen). Such a "yield" for death could be avoided by introducing many different fractions of FPOM with compositions corresponding to the dying organisms. A more realistic description of oxygen and nutrient transformation during mineralization of organic material would be possible by coupling this model to a water quality model. This is beyond the scope of this study. 
Step 2: Allometric scaling of rates.-The individual basal metabolic rate as energy turnover per time is given in Eq. 1. The basal metabolic rate of a population can be estimated by multiplication with the number of individuals $n$ per area $A$ and converted into $\mathrm{g} \mathrm{DM} \cdot \mathrm{m}^{-2} \cdot \mathrm{s}^{-1}$ by division by the typical energy content EC (J/g DM) of the biomass:

$$
r_{\text {basal metab }}=\frac{n}{A} i_{0}\left(\frac{M}{M_{0}}\right)^{b} e^{-E / k T} \frac{1}{\mathrm{EC}} .
$$

The number of individuals $n$ per area $A$ can be estimated from the biomass density $D\left(\mathrm{~g} \mathrm{DM} / \mathrm{m}^{2}\right)$ and the mean individual body mass $M$ :

$$
\frac{n}{A}=\frac{D}{M}
$$

leading to

$$
r_{\text {basal metab }}=D \times i_{0} \frac{M^{b-1}}{M_{0}^{b}} e^{-E / k T} \frac{1}{\mathrm{EC}} .
$$

In most organisms the long-term sustained rate of biological activity is some fairly constant multiple, which is typically about two or three, of the basal metabolic rate (Brown et al. 2004). We therefore introduce the universal factor $f_{\text {resp }}$ and the taxa-specific factors $f_{\text {basal tax }}$ to estimate respiration rates:

$$
r_{\text {resp tax }}=f_{\text {resp }} \times f_{\text {basal tax }} \times r_{\text {basal metab }} .
$$

Analogously, we formulate the mortality rate also as proportional to the basal metabolic rate:

$$
r_{\text {mort tax }}=f_{\text {mort }} \times f_{\text {basal tax }} \times r_{\text {basal metab }} .
$$

The growth of primary producers is formulated dependent on the availability of light, $I$, concentration of dissolved, inorganic phosphorus, $C_{\mathrm{P}}$, concentration of dissolved inorganic nitrogen, $C_{\mathrm{N}}$, and a self-inhibition term accounting for self-shading and diffusion limitation when algal mats become thicker

$$
\begin{aligned}
r_{\text {gro }}^{\mathrm{pp}}= & f_{\text {gro }} \times f_{\text {gro tax }} \times f_{\text {basal tax }} \times r_{\text {basal metab }} \times \frac{I}{K_{I}+I} \\
& \times \min \left(\frac{C_{\mathrm{P}}}{K_{\mathrm{P}}+C_{\mathrm{P}}}, \frac{C_{\mathrm{N}}}{K_{\mathrm{N}}+C_{\mathrm{N}}}\right) \times \frac{K_{\text {dens }}}{K_{\text {dens }}+D} \\
& \times\left(1-f_{\text {shade }}\right)
\end{aligned}
$$

where the light intensity at the river bed is given by $I=I_{0}$ $\times \exp (-\lambda h), \lambda$ is the light extinction coefficient, $h$ water depth, $f_{\text {shade }}$ the shaded fraction of the river surface, $K_{I}$, $K_{\mathrm{P}}$ and $K_{\mathrm{N}}$ the half-saturation constants regarding light, dissolved inorganic phosphorus, and nitrogen, and $K_{\text {dens }}$ the half-inhibition constant regarding self-shading or diffusion limitation, $f_{\text {gro tax }}$ is a taxon-specific modification factor of the growth rate.

The growth of consumers is assumed to depend on the availability of food and on the habitat capacity. The fact that many taxa can feed on different food sources is accounted for by the introduction of one growth process per food source $j$, a food-limitation term for the sum of available food sources $f_{\text {lim food and a preference term }}$ $f_{\text {pref } j}$ that accounts for the availability of the different food sources and on food preferences of the taxa and describes adaptive foraging. Here, $p_{j}$ is the preference coefficient for food source $j$. By setting all $p_{j}$ to unity (or all $p_{j}$ to the same value), opportunistic foraging can be simulated that depends only on the availability of food sources:

$$
\begin{aligned}
r_{\text {gro on } j}^{\text {cons }}= & f_{\text {gro }} \times f_{\text {gro tax }} \times f_{\text {lim food }} \times f_{\text {pref } j} \times f_{\text {self inh }} \\
& \times f_{\text {basal tax }} \times r_{\text {basal metab }} \\
f_{\text {lim food }}= & \frac{D_{\text {food }}^{q}}{K_{\text {food }}^{q}+D_{\text {food }}^{q}} \\
f_{\text {pref } j}= & \frac{D_{j} p_{j}}{\sum_{f} D_{f} p_{f}} .
\end{aligned}
$$

Here, $D_{\text {food }}$ is the sum of the surface densities of all food sources $\left(\mathrm{g} \mathrm{DM} / \mathrm{m}^{2}\right)$, if food is SusPOM, we multiply the concentration in $\mathrm{g} \mathrm{DM} / \mathrm{m}^{3}$ by the typical height of the water column the organisms are able to filter $\left(h_{\text {filt }}\right)$ and $K_{\text {food }}$ is the half-saturation constant for food (g DM/ $\left.\mathrm{m}^{2}\right), q$ is a parameter to switch between different functional forms of food limitation $(q=1$ leads to a Monod or Holling Type II functional response, $q=2$ leads to a Holling Type III), $f_{\text {gro tax }}$ is a taxon-specific modification factor of the growth rate. The different feeding types of different invertebrate taxa were derived from the trait databases freshwaterecology.info (available online) ${ }^{2}$ and CASiMiR (Kopecki and Schneider 2010; Institut für Wasserbau, Universität Stuttgart, unpublished database).

To consider the limitation in habitat capacity leading to intraspecific competition, a self-inhibition term is introduced which decreases the growth rate with increasing biomass density of the taxon. $K_{\text {dens }}$ is a parameter to characterize the density where the growth rate is reduced to $50 \%$. We implemented two versions, the Monod (Eq. 14) and the Blackman formulation (Eq. 15):

$$
\begin{aligned}
f_{\text {self inh Monod }} & =\frac{K_{\text {dens }}}{K_{\text {dens }}+D} \\
f_{\text {self inh Blackman }} & =\left\{\begin{array}{cl}
1-\frac{D}{2 K_{\text {dens }}} & \text { for } D<2 K_{\text {dens }} \\
0 & \text { for } D \geq 2 K_{\text {dens }} .
\end{array}\right.
\end{aligned}
$$

From the stoichiometric coefficients (Table 1) and the dynamic rates, differential equations can be constructed according to Eq. 2. An example is given for a consumer $i$

2 www.freshwaterecology.info 
TABLE 2. Model input: environmental conditions for each site.

\begin{tabular}{|c|c|c|c|}
\hline & & & Site \\
\hline Symbol & Description & Unit & $\begin{array}{c}\text { MA167, } \\
\text { Gossauerbach } \\
\text { up WWTP }\end{array}$ \\
\hline$T$ & mean temperature & ${ }^{\circ} \mathrm{C}$ & 10.3 \\
\hline$T_{\text {class }}$ & temperature class & & moderate \\
\hline$L$ & length of the river reach & $\mathrm{m}$ & 100 \\
\hline$w$ & mean width of the river reach & $\mathrm{m}$ & 2 \\
\hline$I_{0}$ & light intensity at the river bed without shading & $\mathrm{W} / \mathrm{m}^{2}$ & 125 \\
\hline$f_{\text {shade }}$ & fraction of water surface shaded by trees & & 0.15 \\
\hline$C_{\mathrm{SusPOM}}^{\dagger}$ & typical concentration of SusPOM & $\mathrm{g} \mathrm{DM} / \mathrm{m}^{3}$ & 0.9 \\
\hline $\operatorname{Lit}_{\text {Inp }}{ }^{\dagger}$ & mean input of leaf litter & $\mathrm{g} \mathrm{DM} \cdot \mathrm{m}^{-2} \cdot \mathrm{yr}^{-1}$ & 170 \\
\hline Cur class & current regime & & high \\
\hline Substr & substrate/microhabitat classes, cf. Table A4 & & $\begin{array}{l}\text { psa, aka, mil, mal, } \\
\text { hpe, alg, pom }\end{array}$ \\
\hline OrgCont & pollution with organic contaminants & yes/no & yes/no \\
\hline Sapro & saprobic zone & & oligo \\
\hline$C_{\mathrm{P}}$ & phosphate concentration & $\mathrm{mg} \mathrm{P} / \mathrm{L}$ & 0.01 \\
\hline$C_{\mathrm{N}}$ & typical $\mathrm{N}$ concentration & $\mathrm{mg} \mathrm{N} / \mathrm{L}$ & 3.3 \\
\hline
\end{tabular}

Notes: Included with site IDs is the name of the stream and whether it is upstream (up) or downstream (dn) of a wastewater treatment plant (WWTP). Abbreviations are: psa, psammal; aka, akal; mil, micro-/mesolithal; mal, macro-/megalithal; hpe, hygropetric habitats; alg, algae; pom, particulate organic matter; oligo, water quality corresponding to oligo-saprobic conditions; $\beta$-meso, water quality corresponding to $\beta$-meso-saprobic conditions.

$\dagger$ Input with a relative standard deviation of 0.25 .

feeding on only one food source $j$ and having only one predator $k$ :

$$
\begin{aligned}
\frac{d B_{\text {cons } i}}{d t}=( & \left(f_{\text {gro }} \times f_{\text {gro tax } i} \times f_{\text {lim food } i} \times f_{\text {pref } i j} \times f_{\text {self inh } i}\right. \\
- & \left.f_{\text {resp }}-f_{\text {mort }}\right) \times f_{\text {basal tax } i} \times r_{\text {basal metab } i} \\
- & {\left[\frac{1}{Y_{\text {gro }}} \times f_{\text {gro }} \times f_{\text {gro tax } k} \times f_{\text {lim food } k} \times f_{\text {pref } k_{i}}\right.} \\
& \left.\left.\times f_{\text {self inh } k} \times f_{\text {basal tax } k} \times r_{\text {basal metab } k}\right]\right) w
\end{aligned}
$$

Note that we assume the factors $f_{\text {gro }}, f_{\text {resp }}$, and $f_{\text {mort }}$ as well as the parameters $i_{0}, b$, and $E$ to be universal for all invertebrate taxa (these parameters are different for periphyton and invertebrates, however) and $r_{\text {basal metab } i}$ to depend via the individual body mass on the taxa. For invertebrates, we used prior parameter estimates of $i_{0}, b$, and $E$ from Ehnes et al. (2011) as they are based on the largest collection of invertebrate data and because they fitted all three parameters jointly. For periphyton, we defined prior parameter distributions according to Tang and Peters (1995) and Tang (1995).

Step 3: Modify rates based on trait information and environmental conditions.-Different invertebrate taxa are adapted to different environmental conditions. Therefore, environmental factors like temperature, current, and water quality have different effects on invertebrate taxa. Suboptimal or even intolerable conditions can influence growth and death rates or induce drift.
We model the effect of habitat conditions regarding current, temperature regime, and substrate/microhabitat conditions on the community composition using information from the trait database freshwaterecology.info (see footnote 2) on the tolerance of different taxa:

$$
K_{\text {dens }}=h_{\text {dens }} \times f_{\text {current }} \times f_{\text {temp }} \times f_{\text {substrate }}
$$

with $f_{\text {current }}$ the factor regarding current tolerance, $f_{\text {temp }}$ the factor regarding temperature tolerance, and $f_{\text {substrate }}$ the factor regarding substrate/microhabitat tolerance. These factors can take values between 0 and 1 depending on environmental conditions. The parameterizations of these factors are given in Appendix: Tables A2-A4. Currently, information on temperature and substrate tolerances is available only for Ephemeroptera, Plecoptera, Trichoptera, and partly for Chironomidae. For taxa where this information is missing, the factors are set to 1 .

To account for toxic effects of organic contaminants (e.g., pesticides, insecticides) on invertebrate taxa, we implemented an increase of the mortality rate for sensitive taxa at contaminated sites. As an estimation of the sensitivity of taxa we used the SPEAR database (Liess et al. 2008) that divides taxa into species at risk and species not at risk according to four different traits (database available online). ${ }^{3}$ The death rate (Eq. 9) is

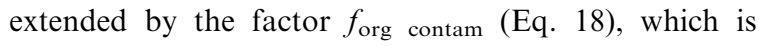
chosen dependent on the classification as species at risk or species not at risk and the contamination of the site

$$
r_{\text {mort }}=f_{\text {mort }} \times f_{\text {org contam }} \times f_{\text {saproby }} \times f_{\text {basal tax }} \times r_{\text {basal metab }} .
$$

\footnotetext{
${ }^{3}$ http://www.systemecology.eu/SPEAR
} 
TABle 2. Extended.

\begin{tabular}{lll}
\hline \hline & \multicolumn{2}{c}{ Site } \\
\hline $\begin{array}{c}\text { MA168, } \\
\text { dn WWTP }\end{array}$ & $\begin{array}{c}\text { MA437, } \\
\text { Lieburgerbach } \\
\text { up WWTP }\end{array}$ & $\begin{array}{c}\text { MA438, } \\
\text { Lieburgerbach } \\
\text { dn WWTP }\end{array}$ \\
\hline 12.4 & 9.6 & 11.4 \\
warm & moderate & warm \\
100 & 100 & 100 \\
2 & 5 & 4.5 \\
125 & 125 & 125 \\
0.26 & 0.90 & 0.95 \\
0.9 & 0.9 & 0.9 \\
260 & 500 & 420 \\
high & high & moderate \\
psa, aka, mil, mal, & psa, aka, mil, & psa, aka, mil, \\
hpe, alg, pom & mal, alg, pom & mal, alg, pom \\
yes & no & yes \\
$\beta-m e s o$ & oligo & $\beta-m e s o$ \\
0.03 & 0.05 & 0.04 \\
8.0 & 2.1 & 7.6 \\
\hline
\end{tabular}

As the simplest implementation, we set the factor $f_{\text {org contam }}$ for "insensitive" taxa to 1 , for "sensitive" taxa to 1 at uncontaminated sites and to the value $c_{\text {org contam crit }}$ at contaminated sites. This describes the simplistic assumption that the death rate of sensitive taxa is increased by a factor of $c_{\text {org contam crit }}$ at sites with organic contaminants in the water. Tolerance to water quality aspects described by the saprobic system is implemented analogously using the information from the Austrian saprobic system (cf Appendix: Table A5).

Step 4: Get site-specific information.-As a first test, the model was applied to four sites in the catchment of the Mönchaltorfer Aa river near Zurich on the Swiss Plateau. The two pairs of sites from two streams are each upstream and 300-400 $\mathrm{m}$ downstream of a wastewater treatment plant (WWTP) with a fraction of treated wastewater of about $40 \%$ (MA168) and $20 \%$ (MA438), respectively. For these sites, invertebrate data collected between 1982 and 2005 were provided by the Office for Waste, Water, Energy, and Air of the Canton of Zurich (AWEL Zurich). The estimated environmental conditions used as model input are given in Table 2. A description of how we estimated the conditions from available cantonal monitoring data is given in Appendix: Table A6.

As a first step, the source pool of taxa occurring in the whole catchment were determined. This was done by analyzing available monitoring data. Simulations were run for a list of 28 macroinvertebrate taxa. Taxa occurring in fewer than five of the 87 available samples from the catchment were excluded. Further dispersal filters were not applied since at the size of this catchment (about $50 \mathrm{~km}^{2}$ ) we assume that dispersal limitation is not a factor that influences long-term average community composition. We performed the simulations at the genus level since a higher taxonomic resolution was available only for part of the observational data. For the source pool taxa, the mean individual biomass was estimated from length-mass relationships (Appendix: Table A1).

Step 5: Perform simulations. - The model calculates the (bio)mass development of the state variables over time under the forcing of external influence factors. For the model test, we worked with constant external forcing (Table 2) and assess local occurrence of taxa from the long-term equilibrium. The term "occurrence" is used here in the sense of an equilibrium biomass above an abundance threshold of 0.5 individuals $/ \mathrm{m}^{2}$ where observation in the field would be likely. This threshold depends on the sampling strategy and was estimated for the cantonal monitoring data we use for inference in step 6. We chose the same initial biomass density of $1 \mathrm{~g} \mathrm{DM} /$ $\mathrm{m}^{2}$ for all invertebrate taxa of the source pool. However, tests showed that model results are not sensitive to this choice, since stable equilibria are reached irrespective of the initial conditions.

To estimate uncertainty of model results due to parameter uncertainty, we define marginal (prior) probability distributions for the parameters given in the Appendix: Table A1 and assume independence to construct their joint distribution. We propagate this distribution to the model results numerically by randomly drawing from this distribution and calculating corresponding model results.

The model was implemented with the statistics and graphics software R (R Development Core Team 2011). The code is given in the Supplement. The differential equations were solved with the $\mathrm{R}$ package deSolve (Soetaert et al. 2010).

Step 6: Bayesian inference.-For all sites, we determined those taxa that occurred in all samples and those taxa that never occurred in any sample at that site. We used only the observational data from 1995 to 2005. Data from the 1980s were not included because the taxonomic resolution of these samples was lower and environmental influence factors changed by that time. We conditioned the prior parameter distribution by the observed occurrence pattern of taxa rather than by quantitative density estimates. Observed densities depend very much on short term dynamics in the system. Since we estimated occurrence of taxa by using constant environmental influence factors, the short-term dynamics in biomass development are not represented by the model and quantitative density estimates are not expected to match observed ones. The pattern-oriented conditioning is numerically implemented by selecting those parameter samples that correspond to simulations that fulfill the following two criteria: (1) all taxa that occurred in all observations at a specific site are predicted to occur by the model run and (2) all taxa that never occur in the observations at a specific site are predicted to not occur by the model run. Note that this acceptance-rejection technique is a simple form of a "likelihood-free" (without evaluation of the likelihood function) implementation of Bayesian inference as used in approximate Bayesian computation (e.g., Marjoram et al. 2003). Due to the use 


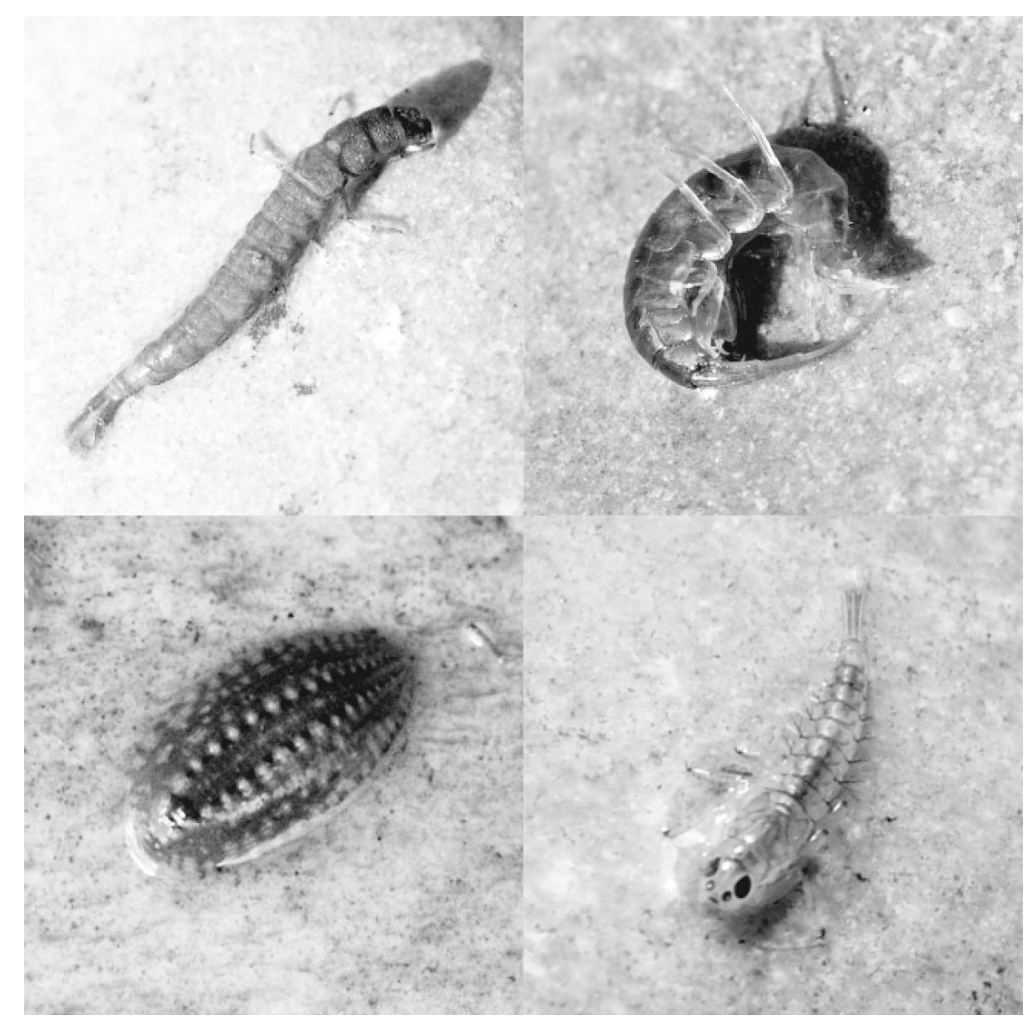

Plate 1. Benthic macroinvertebrates from a site close to the catchment of the Mönchaltorfer Aa, Switzerland. From left to right (and from top to bottom): caddisfly (Trichoptera), amphipod (Amphipoda, Gammaridae), leech (Hirudinea), mayfly (Ephemeroptera, Baetidae). Photo credits: Raoul Schaffner.

of discrete output pattern, it is not approximate in the same sense in our context. Comparing the resulting posterior parameter sample with the prior, we can analyze for which parameters we can learn from the data. If specific taxa are systematically over- or underestimated by the model for most of the prior parameter samples, it can happen that the criteria are never fulfilled and a posterior parameter sample cannot be derived. Such cases are of special interest, since those systematic differences can provide hints for model improvement or indicate the need for the revision of model input estimation. In such cases we excluded these taxa from the criteria to derive a posterior parameter sample and analyzed if we can learn something about the parameters from the other taxa.

\section{RESULTS}

Even without fitting parameter values, the model is able to predict key patterns of observed occurrence of taxa quite well, as shown by food webs resulting from the deterministic model with parameters fixed at the mean of their marginal prior distributions (Fig. 1). Note, that it was not known beforehand if site MA167 is polluted with organic contaminants or not. We therefore ran the model under both assumptions. Model results clearly show that a compliance of model results with observations is achieved only by assuming organic pollution at that site (Fig. 1,
Table 3). Model results were not sensitive to choosing a value of $q$ of 1 or 2 in Eq. 12 for food-limitation and to choosing Eqs. 14 or 15 for self-inhibition, indicating high structural stability of the model. Therefore, we show here only the results for $q=1$ and using Eq. 14 .

To account for parameter uncertainty, we calculate the probability to exceed the abundance threshold of 0.5 individuals $/ \mathrm{m}^{2}$ for all taxa from Monte Carlo simulations. Results are given in Table 3 for each site, grouped according to the occurrence in observations. For most taxa that occurred in all samples of a site, the model predicts a high probability to occur, and for most taxa never occurring in the samples of a site, the model predicts a low probability to occur. However, there are exceptions where the model is not in compliance with observations. This is the case, e.g., for the leech Glossiphonia, with a probability to occur between 0.4 and 0.54 at three sites where it was never observed (see Discussion) and for Radix at site MA437. Taxa with a low predicted probability to occur that occurred in all samples are, e.g., Habroleptoides at site MA437 or Ecdyonurus and Rhyacophila at site MA438.

The marginals of the prior and the posterior parameter distribution resulting from conditioning with the data of all four sites are shown in Fig. 2. We depicted those parameters with pronounced differences between prior and posterior marginals. As the model is relatively 

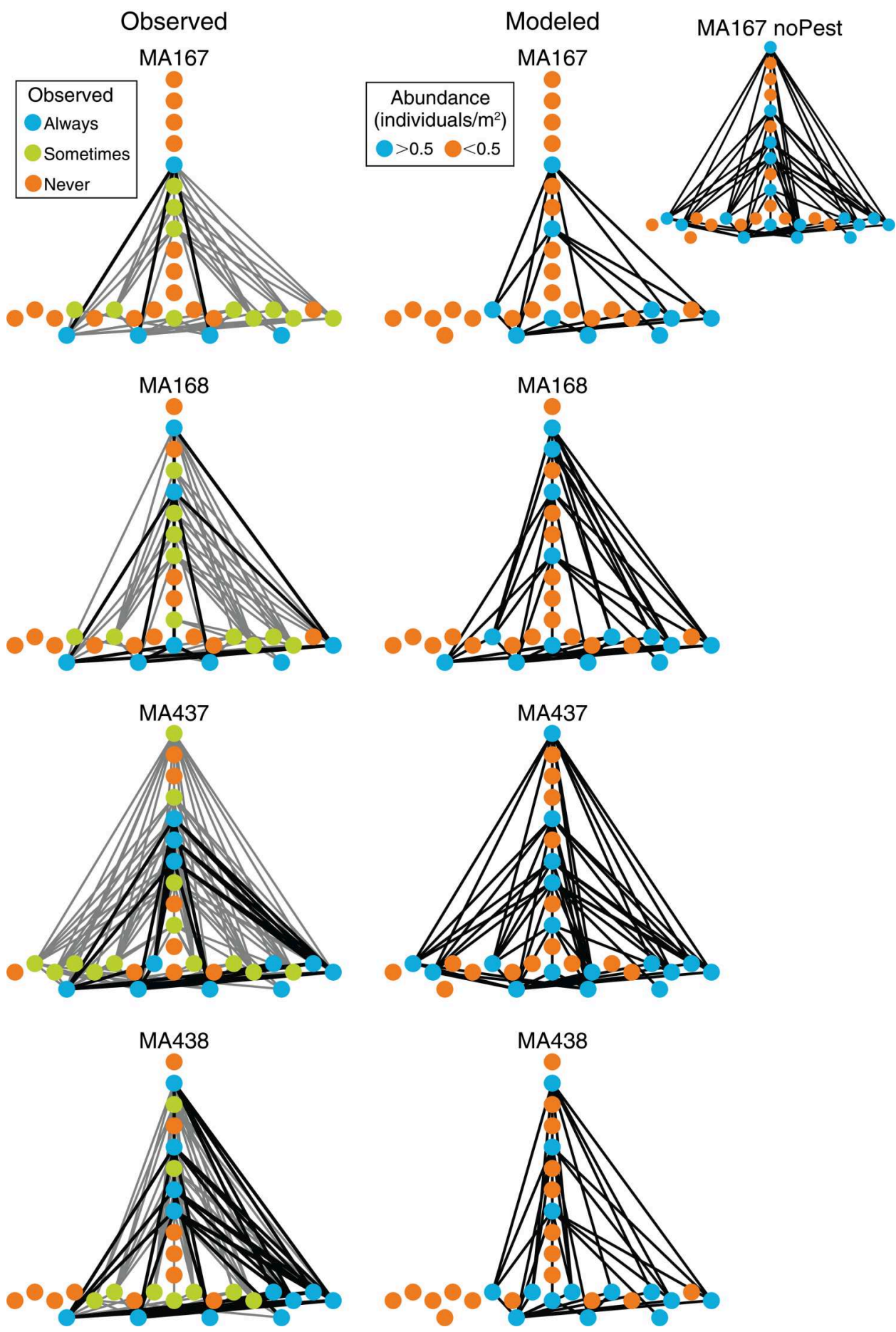

FIG. 1. Food webs at four different sites (MA167, MA168, MA437, and MA438). Lines represent feeding links, dots represent different invertebrate taxa, except four dots along the base represent periphyton, fine particulate organic matter (FPOM), leaf litter, and suspended particulate organic matter (SusPOM) from left to right. The same invertebrate taxa appear in the same position on each panel. Diagrams on the left-hand side show food webs constructed from observational data with taxa present in all samples (blue), taxa absent in all samples (orange), and taxa occurring in part of the samples (green with grey lines for feeding links). Diagrams on the right-hand side show food webs constructed from model results of deterministic simulations with parameters fixed at the mean of the marginal prior distributions (Appendix: Table A1), with taxa with an equilibrium abundance of at least 0.5 individuals $/ \mathrm{m}^{2}$ (blue), and other taxa (orange). Modeled data are shown for site MA167 assuming pollution with organic contaminants (large diagram) and no pollution with organic contaminants (small diagram). 
TABLE 3. Predicted probability (Prob.) of exceeding an abundance of $>0.5$ individuals $/ \mathrm{m}^{2}$ for taxa that occurred in all samples (always observed), in none of the samples (never observed), and in some of the samples (sometimes observed) at the respective sites.

\begin{tabular}{|c|c|c|c|c|c|c|c|c|}
\hline \multicolumn{3}{|c|}{ MA167 } & \multicolumn{2}{|l|}{ MA168 } & \multicolumn{2}{|l|}{ MA437 } & \multicolumn{2}{|l|}{ MA438 } \\
\hline Taxa & $\begin{array}{l}\text { Prob., } \\
\text { pest }\end{array}$ & $\begin{array}{l}\text { Prob., } \\
\text { no pest }\end{array}$ & Taxa & Prob. & Taxa & Prob. & Taxa & Prob. \\
\hline Always observed & & & Always observed & & Always observed & & Always observed & \\
\hline Gammarus & 0.92 & 0.89 & Baetis & 0.61 & Habroleptoides & 0.01 & Rhyacophila & 0.01 \\
\hline Never observed & & & Erpobdella & 0.62 & Atherix & 0.18 & Ecdyonurus & 0.04 \\
\hline Habrophlebia & 0 & 0.01 & Gammarus & 0.88 & Ecdyonurus & 0.42 & Baetis & 0.42 \\
\hline Stylodrilus & 0.01 & 0.01 & Radix & 0.89 & Baetis & 0.49 & Hydropsyche & 0.47 \\
\hline Ephemera & 0.01 & 0.02 & Never observed & & Eiseniella & 0.58 & Eiseniella & 0.48 \\
\hline Habroleptoides & 0.02 & 0.01 & Habrophlebia & 0.00 & Rhyacophila & 0.89 & Elmis & 0.52 \\
\hline Dugesia & 0.02 & 0.01 & Ephemera & 0.00 & Gammarus & 0.90 & Erpobdella & 0.57 \\
\hline Calopteryx & 0.04 & 0.40 & Stylodrilus & 0.01 & Never observed & & Gammarus & 0.90 \\
\hline Rhithrogena & 0.04 & 0.13 & Habroleptoides & 0.01 & Habrophlebia & 0.01 & Never observed & \\
\hline Ecdyonurus & 0.08 & 0.46 & Rhithrogena & 0.07 & Dugesia & 0.01 & Habrophlebia & 0.00 \\
\hline Dicranota & 0.08 & 0.06 & Dicranota & 0.08 & Rhithrogena & 0.01 & Rhithrogena & 0.00 \\
\hline Paraleptophlebia & 0.08 & 0.51 & Ecdyonurus & 0.09 & Dicranota & 0.04 & Dugesia & 0.01 \\
\hline Erpobdella & 0.1 & 0.12 & Paraleptophlebia & 0.10 & Erpobdella & 0.13 & Dicranota & 0.02 \\
\hline Nemoura & 0.23 & 0.83 & Protonemura & 0.18 & Paraleptophlebia & 0.48 & Calopteryx & 0.02 \\
\hline Protonemura & 0.24 & 0.81 & Nemoura & 0.19 & Glossiphonia & 0.54 & Gyraulus & 0.02 \\
\hline Leuctra & 0.26 & 0.87 & Leuctra & 0.22 & Radix & 0.94 & Paraleptophlebia & 0.04 \\
\hline Odontocerum & 0.34 & 0.94 & Odontocerum & 0.32 & Sometimes observed & & Protonemura & 0.16 \\
\hline Glossiphonia & 0.4 & 0.55 & Glossiphonia & 0.41 & Simulium & 0.01 & Nemoura & 0.20 \\
\hline Sometimes observed & & & Sometimes observed & & Stylodrilus & 0.01 & Leuctra & 0.19 \\
\hline Simulium & 0.01 & 0.00 & Simulium & 0.00 & Ephemera & 0.02 & Odontocerum & 0.33 \\
\hline Atherix & 0.02 & 0.20 & Atherix & 0.01 & Gyraulus & 0.04 & Sometimes observed & \\
\hline Gyraulus & 0.04 & 0.04 & Calopteryx & 0.02 & Asellus & 0.28 & Simulium & 0.00 \\
\hline Rhyacophila & 0.28 & 0.87 & Gyraulus & 0.02 & Calopteryx & 0.38 & Atherix & 0.01 \\
\hline Asellus & 0.29 & 0.27 & Dugesia & 0.03 & Riolus & 0.52 & Ephemera & 0.04 \\
\hline Baetis & 0.57 & 0.53 & Rhyacophila & 0.07 & Hydropsyche & 0.55 & Glossiphonia & 0.33 \\
\hline Riolus & 0.58 & 0.56 & Hydropsyche & 0.63 & Elmis & 0.56 & Habroleptoides & 0.36 \\
\hline Hydropsyche & 0.59 & 0.57 & Eiseniella & 0.63 & Protonemura & 0.83 & Stylodrilus & 0.48 \\
\hline Eiseniella & 0.6 & 0.61 & Riolus & 0.67 & Nemoura & 0.85 & Riolus & 0.48 \\
\hline Elmis & 0.62 & 0.60 & Elmis & 0.71 & Leuctra & 0.88 & Asellus & 0.90 \\
\hline Radix & 0.94 & 0.93 & Asellus & 0.88 & Odontocerum & 0.94 & Radix & 0.91 \\
\hline
\end{tabular}

Note: For site MA167, model runs were performed assuming pollution by organic contaminants (pest) and no pollution by organic contaminants (no pest).

complex and the data are scarce, these differences are still quite small. Results indicate that the model fits better to observed data when, e.g., the growth rates of invertebrates $f_{\text {gro }}$ are shifted to lower values and the respiration rates of invertebrates $f_{\text {resp }}$, the normalization constant $i_{0}$, and the parameter that increases death rates of sensitive taxa at sites polluted with organic contaminants, $c_{\text {org contam crit }}$, are shifted to higher values. This illustrates how we can update our knowledge about parameters from comparison with observations. Note, that for site MA437 the taxa Radix, Glossiphonia, Habroleptoides, Atherix, Ecdyonurus, and Baetis and for site MA438 the taxa Ecdyonurus, Rhyacophila, Baetis, Hydropsyche, and Eiseniella had to be excluded from the inference criteria to get an acceptable posterior sample size. Thereby we lose information for inference from data. However, by analyzing underlying reasons for systematic deviations in prediction of these taxa that cannot be explained by parameter uncertainty, indications for model improvement can be gained.

\section{Discussion}

Results show that the model is able to reproduce key patterns of coexistence of different invertebrate taxa.
This is remarkable and an indication that the suggested model makes a relevant step towards fruitfully combining knowledge from theoretical ecology and real invertebrate traits. A similar approach was followed by Boit et al. (2012) who developed a mechanistic food web model that describes 24 guilds of the pelagic zone of Lake Constance based on allometric scaling to reproduce observed patterns of seasonal plankton succession. This indicates that the combination of mechanistic food web models with allometric scaling might be a promising way to model other multi-trophic ecosystems as well.

The analysis of remaining discrepancies between our model results and observations regarding the occurrence of taxa helps improve the model in the future. Reasons for such discrepancies can be model structure uncertainty (e.g., missing environmental influence factors, missing or wrong formulation of processes), parameter uncertainty, missing or uncertain trait classification of taxa, input uncertainty regarding environmental influence factors (e.g., organic pollution at site MA167), or observation errors (i.e., missing or misclassification of taxa, inadequate taxonomic resolution). For example, at sites MA167, MA168, and MA437, the leech Glossiphonia was never observed but is predicted by the model to 

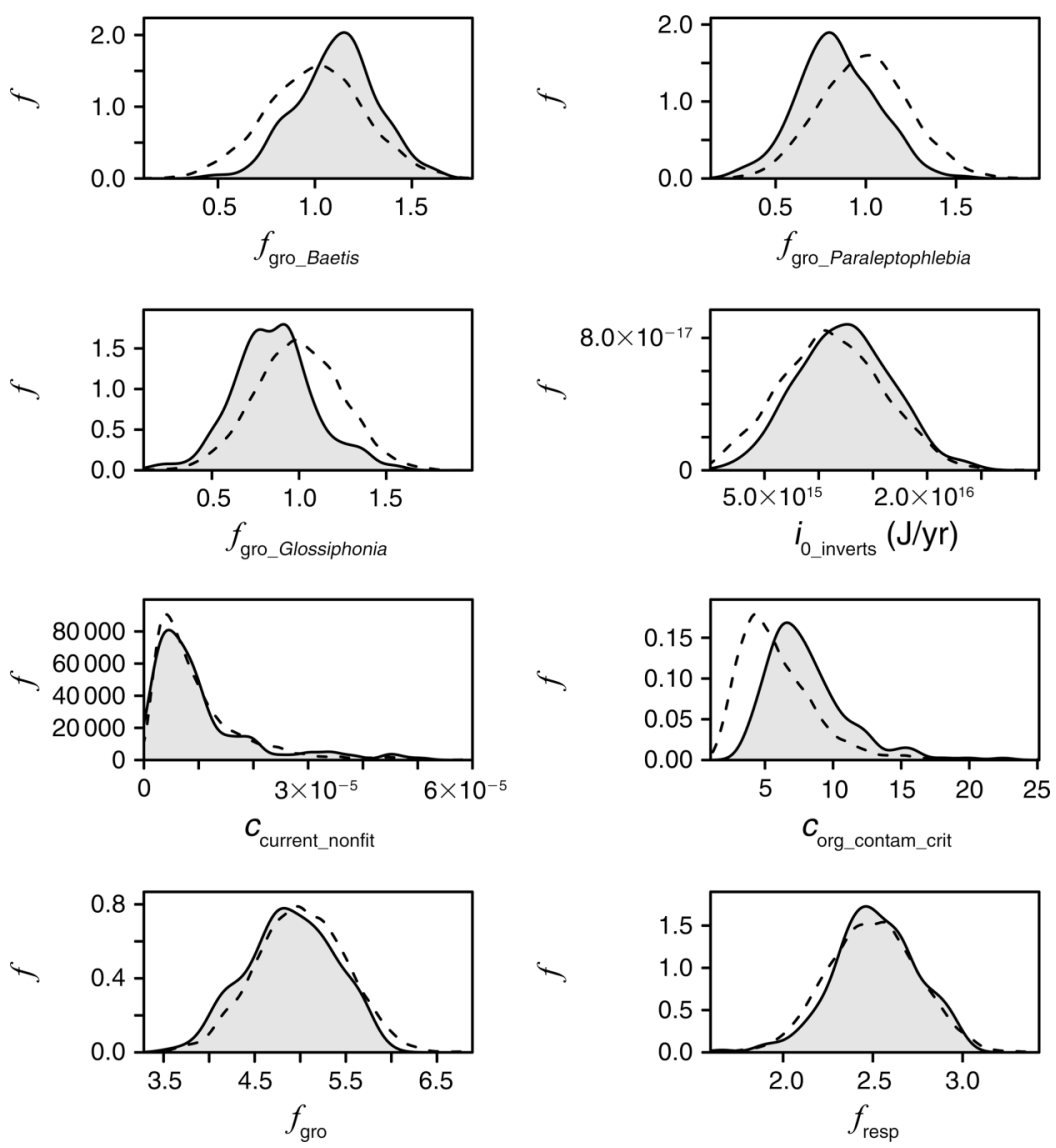

FIG. 2. Comparison of marginal prior (dashed lines) and posterior (solid lines with gray shading underneath) parameter distributions. The posterior shown here is resulting from conditioning with the data of all four sites; the $x$-axis shows parameter values for the taxon-specific multiplicative factors regarding growth $\left(f_{\text {gro_Baetis }}, f_{\text {gro_Paraleptophlebia }}, f_{\text {gro_Glossiphonia }}\right)$, normalization constant for metabolic rates of invertebrates $i_{0}$, factor regarding current tolerance at current conditions not fitting to the trait of the

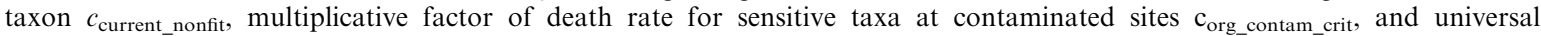
multiplicative factor regarding growth and respiration for invertebrates $f_{\text {gro }}, f_{\text {resp }}$ (dimensions given in Appendix A: Table A1); the $y$-axis shows probability density of frequency of occurrence $f$.

occur at these sites with a probability of $0.4-0.54$. This taxon is classified as predator in both trait databases (CASiMiR and freshwaterecology.info) and there is no severe food limitation. According to its trait classification and the estimation of environmental conditions, the taxon is not negatively affected by water quality. However, only one of the four species from the genus Glossiphonia has only one point assigned to oligotrophic conditions. Therefore, it is possible that negative effects of the saprobic conditions at sites MA167 and MA437 are underestimated by the model. A stricter implementation of the tolerance to environmental conditions and a higher taxonomic resolution could improve model accuracy. A classification regarding current, temperature and microhabitat tolerances is not available for this taxon. This could be another reason for overestimating its occurrence. Further investigating the reasons by literature studies and application of the model to more sites to test if this is a general deficiency of our model regarding this taxon or if it is specific to the test sites, would help improve our understanding and the predictive capabilities of the model. Due to our implementation, missing trait information may lead to an overestimation of the affected taxa. To overcome this problem, phylogenetic information could be used to estimate missing traits from related taxa, as it was done by Bruggeman (2011) for phytoplankton.

In general, all environmental models are wrong (see Box and Draper 1987) since they are always a simplification of much more complex natural systems. The art of model development is to find an adequate compromise between complexity and simplicity. However, increasing the complexity of models is only possible, if adequate knowledge is available, and it is only desirable, if universality and/or predictive capabilities of the model increase. Since knowledge about many processes (e.g., the influence of chemical contaminants on metabolic rates of macroinvertebrates) is incomplete, we tried to find simple empirical descriptions that allow us to reproduce observable patterns and avoid unjusti- 
fiable assumptions. For example, we implemented ecotoxic effects by a binary classification of taxa into sensitive and insensitive taxa as well as a binary classification of sites into polluted and unpolluted sites using the database underlying the SPEAR concept (Liess et al. 2008). A more precise description of ecotoxic effects is desirable but so far impeded by the limited availability of data regarding effects of a multitude of contaminants on the variety of taxa, unknown exposure patterns at the different sites, and various factors that influence the transferability of laboratory experiments to field conditions. Mechanistically more detailed approaches use state variables that are not directly observable and involve many more model parameters (e.g., the DEB and DEBtox models [Kooijman and Bedaux 1996, Billoir et al. 2009, Kooijman 2010, Jager and Zimmer 2012]). This makes these models difficult to apply for modeling benthic communities consisting of many different taxa with poorly known properties. As we also have poor knowledge on uptake and release rates of toxicants, relevant organs or tissues where they accumulate, and critical concentrations, we are also not considering internal toxicant concentrations, as suggested by Jager et al. (2011). The results presented in this paper indicate that our model is based on an adequate compromise between complexity and simplicity. However, if more detailed information for the variety of invertebrate taxa and a better characterization of field conditions becomes available, the model could be improved to describe ecotoxic effects more accurately.

The model Streambugs 1.0 requires mainly input that can be estimated from data that are statewide available. This is a huge advantage, since it can be tested at all sites in an ecoregion where invertebrate monitoring data and environmental influence factors are available or can be estimated. Applying the model to a wider range of sites will contribute to inference on model parameters, improving process formulations, and potentially reveal the need to include further processes like emergence of insects or dispersal. Therefore, we see the current relevance of this model as a scientific learning tool for integration of quantitative ecological knowledge and testing of hypotheses on ecosystem functionality. Moreover, it has huge potential for practical application. Moving on to a spatial explicit model that includes dispersal and predicts the benthic meta-community in a river network for given environmental conditions would link to ecological theory of meta-communities and contribute significantly to decision support in river management.

So far, we concentrated on occurrence patterns and their dependence on external influence factors. As we calculate these as steady-state (or long-term dynamic) solutions of a dynamic model, the model could also be used for simulating the dynamics of benthic communities at the taxonomic level. This would considerably extend current approaches at the functional group level
(McIntire and Colby 1978, D'Angelo et al. 1997, Spieles and Mitsch 2003, Schuwirth et al. 2008, 2011). However, to assess the model performance regarding temporal dynamics, data with an appropriate temporal resolution are required. If such data become available, the model would be a very useful tool for assessing temporal aspects of ecosystem functioning and disturbance ecology. Other processes like emergence, flood-induced drift, and recolonization could then be included in the model.

\section{ACKNOWLEDGMENTS}

This study is part of the project iWaQa funded by the SNF (NRP61 on Sustainable Water Management) and the Swiss Federal Office for the Environment (FOEN). We thank C. Stamm, C. T. Robinson, and M. O. Gessner for sharing their knowledge and helpful comments to an earlier version of the manuscript, and R. Siber and M. Müller for processing of data. Monitoring data were kindly provided by the Office for Waste, Water, Energy and Air of the Canton of Zurich (AWEL Zurich). We thank A. Schmidt-Kloiber, M. Liess, and I. Kopecki for giving us access to the trait database freshwaterecology.info, the SPEAR database, and the CASiMiR database, respectively.

\section{Literature Cited}

Andersen, T., J. J. Elser, and D. O. Hessen. 2004. Stoichiometry and population dynamics. Ecology Letters 7:884-900.

Billoir, E., A. da Silva Ferrão-Filho, M. L. Delignette-Muller, and S. Charles. 2009. DEBtox theory and matrix population models as helpful tools in understanding the interaction between toxic cyanobacteria and zooplankton. Journal of Theoretical Biology 258:380-388.

Boit, A., N. D. Martinez, R. J. Williams, and U. Gaedke. 2012. Mechanistic theory and modelling of complex food-web dynamics in Lake Constance. Ecology Letters 15:594-602.

Box, G. E. P., and N. R. Draper. 1987. Empirical modelbuilding and response surfaces. John Wiley, New York, New York, USA.

Brose, U. 2008. Complex food webs prevent competitive exclusion among producer species. Proceedings of the Royal Society B 275:2507-2514.

Brose, U., R. J. Williams, and N. D. Martinez. 2006. Allometric scaling enhances stability in complex food webs. Ecology Letters 9:1228-1236.

Brown, J. H., J. F. Gillooly, A. P. Allen, V. M. Savage, and G. B. West. 2004. Toward a metabolic theory of ecology. Ecology 85:1771-1789.

Bruggeman, J. 2011. A phylogenetic approach to the estimation of phytoplankton traits. Journal of Phycology 47:52-65.

Clark, J. S., M. Dietze, S. Chakraborty, P. K. Agarwal, I. Ibanez, S. LaDeau, and M. Wolosin. 2007. Resolving the biodiversity paradox. Ecology Letters 10:647-662.

D’Angelo, D. J., S. V. Gregory, L. R. Ashkenas, and J. L. Meyer. 1997. Physical and biological linkages within a stream geomorphic hierarchy: a modeling approach. Journal of the North American Benthological Society 16:480-502.

Doledec, S., N. Phillips, and C. Townsend. 2011. Invertebrate community responses to land use at a broad spatial scale: trait and taxonomic measures compared in New Zealand rivers. Freshwater Biology 56:1670-1688.

Ehnes, R. B., B. C. Rall, and U. Brose. 2011. Phylogenetic grouping, curvature and metabolic scaling in terrestrial invertebrates. Ecology Letters 14:993-1000.

Elser, J. J., W. F. Fagan, R. F. Denno, D. R. Dobberfuhl, A. Folarin, A. Huberty, S. Interlandi, S. S. Kilham, E. McCauley, K. L. Schulz, E. H. Siemann, and R. W. Sterner. 
2000a. Nutritional constraints in terrestrial and freshwater food webs. Nature 408:578-580.

Elser, J. J., and R. P. Hassett. 1994. A stoichiometric analysis of the zooplankton-phytoplankton interaction in marine and fresh-water ecosystems. Nature 370:211-213.

Elser, J. J., R. W. Sterner, E. Gorokhova, W. F. Fagan, T. A. Markow, J. B. Cotner, J. F. Harrison, S. E. Hobbie, G. M. Odell, and L. J. Weider. 2000b. Biological stoichiometry from genes to ecosystems. Ecology Letters 3:540-550.

Glazier, D. S. 2009. Metabolic level and size scaling of rates of respiration and growth in unicellular organisms. Functional Ecology 23:963-968.

Guisan, A., and W. Thuiller. 2005. Predicting species distribution: offering more than simple habitat models. Ecology Letters 8:993-1009.

Hairston, N. G., F. E. Smith, and L. B. Slobodkin. 1960. Community structure, population control, and competition. American Naturalist 94:421-425.

Heckmann, L., B. Drossel, U. Brose, and C. Guill. 2012. Interactive effects of body-size structure and adaptive foraging on food-web stability. Ecology Letters 15:243-250.

Hessen, D. O., P. J. Faerovig, and T. Andersen. 2002. Light, nutrients, and P:C ratios in algae: grazer performance related to food quality and quantity. Ecology 83:1886-1898.

Hynes, H. B. N. 1970. The ecology of running waters. Liverpool University Press, Liverpool, UK.

Jager, T., C. Albert, T. G. Preuss, and R. Ashauer. 2011. General unified threshold model of survival - a toxicokinetictoxicodynamic framework for ecotoxicology. Environmental Science and Technology 45:2529-2540.

Jager, T., and E. I. Zimmer. 2012. Simplified dynamic energy budget model for analysing ecotoxicity data. Ecological Modelling 225:74-81.

Kleiber, M. 1947. Body size and metabolic rate. Physiological Reviews 27:511-541.

Kooijman, S. A. L. M. 2010. Dynamic energy budget theory for metabolic organisation. Third edition. Cambridge University Press, Cambridge, UK.

Kooijman, S. A. L. M., and J. J. M. Bedaux. 1996. Analysis of toxicity tests on Daphnia survival and reproduction. Water Research 30:1711-1723.

Kopecki, I., and M. Schneider. 2010. Handbuch für das Habitatssimulationsmodell CASiMiR, Modul: CASiMiRBenthos. Schneider and Jorde Ecological Engineering $\mathrm{GmbH}$, Universität Stuttgart, Institut für Wasserbau, Stuttgart, Germany. www.casimir-software.de/data/CASiMiR_ Benthos_Handb_DE.pdf

Liess, M., R. B. Schafer, and C. A. Schriever. 2008. The footprint of pesticide stress in communities-Species traits reveal community effects of toxicants. Science of the Total Environment 406:484-490.

Marjoram, P., J. Molitor, V. Plagnol, and S. Tavare. 2003. Markov chain Monte Carlo without likelihoods. Proceedings of the National Academy of Sciences USA 100:15324-15328.

May, R. M. 1973. Stability and complexity in model ecosystems. Princeton University Press, Princeton, New Jersey, USA.

McCann, K. S. 2000. The diversity-stability debate. Nature 405:228-233.
McIntire, C. D., and J. A. Colby. 1978. A hierarchical model of lotic ecosystems. Ecological Monographs 48:167-190.

Peters, R. H. 1983. The ecological implications of body size. Cambridge University Press, Cambridge, UK.

Pimm, S. L., and J. H. Lawton. 1978. On feeding on more than one trophic level. Nature 275:542-544.

Poff, N. L. 1997. Landscape filters and species traits: towards mechanistic understanding and prediction in stream ecology. Journal of the North American Benthological Society 16:391-409.

Power, M. E., G. Parker, W. E. Dietrich, and A. Sun. 1995. How does floodplain width affect floodplain river ecology? A preliminary exploration using simulations. Geomorphology 13:301-317.

R Development Core Team. 2011. R: a language and environment for statistical computing. R Foundation for Statistical Computing, Vienna, Austria. http://www. R-project.org/

Reichert, P., and N. Schuwirth. 2010. A generic framework for deriving process stoichiometry in environmental models. Environmental Modelling and Software 25:1241-1251.

Rubner, M. 1883. Über den Einfluss der Körpergrösse auf Stoff- und Kraftwechsel. Zeitschrift für Biologie 19:536-562.

Savage, V. M., J. F. Gillooly, W. H. Woodruff, G. B. West, A. P. Allen, B. J. Enquist, and J. H. Brown. 2004. The predominance of quarter-power scaling in biology. Functional Ecology 18:257-282.

Schuwirth, N., V. Acuna, and P. Reichert. 2011. Development of a mechanistic model (ERIMO-I) for analyzing the temporal dynamics of the benthic community of an intermittent Mediterranean stream. Ecological Modelling 222:91-104.

Schuwirth, N., M. Kuhni, S. Schweizer, U. Uehlinger, and P. Reichert. 2008. A mechanistic model of benthos community dynamics in the River Sihl, Switzerland. Freshwater Biology 53:1372-1392.

Soetaert, K., T. Petzoldt, and R. W. Setzer. 2010. Solving differential equations in R: package deSolve. Journal of Statistical Software 33:1-25.

Spieles, D. J., and W. J. Mitsch. 2003. A model of macroinvertebrate trophic structure and oxygen demand in freshwater wetlands. Ecological Modelling 161:183-194.

Tang, E. P. Y. 1995. The allometry of algal growth rates. Journal of Plankton Research 17:1325-1335.

Tang, E. P. Y., and R. H. Peters. 1995. The allometry of algal respiration. Journal of Plankton Research 17:303-315.

Traas, T. P., J. H. Janse, T. Aldenberg, and T. C. M. Brock. 1998. A food web model for fate and direct and indirect effects of Dursban 4E (active ingredient chlorpyrifos) in freshwater microcosms. Aquatic Ecology 32:179-190.

West, G. B., J. H. Brown, and B. J. Enquist. 1997. A general model for the origin of allometric scaling laws in biology. Science 276:122-126.

White, C. R. 2010. There is no single p. Nature 464:691-693.

Yodzis, P. 1981. The stability of real ecosystems. Nature 289:674-676.

Yodzis, P., and S. Innes. 1992. Body size and consumerresource dynamics. American Naturalist 139:1151-1175.

\section{Supplemental Material}

\section{Appendix}

Tables with model parameters, factors for current and temperature tolerance, substrate/microhabitat and water quality classes, saprobic conditions, and estimation of environmental inputs (Ecological Archives E094-031-A1).

\section{Supplement}

